G433(P) ASSOCIATIONS BETWEEN PRE-INJURY IMPAIRMENT AND THERMAL BURN INJURY IN CHILDREN: ANALYSES OF THE BURNS AND SCALDS ASSESSMENT TEMPLATE (BASAT) DATA

${ }^{1}$ MJ Ikpeme, 'AM Emond, ${ }^{2} J A$ Mytton, 'L Hollen. 'Scar Free Foundation for Children's Burn Research, University of Bristol, Bristol, UK; ${ }^{2}$ Scar Free Foundation for Children's Burn Research, University of West of England, Bristol, UK

10.1136/archdischild-2018-rcpch.422

Aim A systematic review of published research on paediatric burn epidemiology in high income countries indicated a paucity of evidence regarding the association between pre-injury impairment in children and the risk of burn injuries. The aim of this study is to investigate differences in paediatric burn injuries by impairment status.

Methods The Burns and Scalds Assessment Template (BaSAT) was used in A and E departments in England and Wales to collect clinical and socio-demographical information on burn cases. From July 2012-November 2016, 2779 burn cases were recorded of which 1364 were suitable for inferential analyses. In this study, impairment was collated from parents/carers reports of what additional needs their children had (i.e. behavioural versus non-behavioural). The primary outcome was burn type (scalds versus non-scalds). Burn depth (full thickness (FT) versus non FT) and use of cold running water (CRW) first aid were secondary outcomes. Inferential analyses employed multivariable logistic regression in STATA v.14. Variables of interest were $90.1 \%$ to $100 \%$ complete. Unadjusted odds ratios (OR) and adjusted OR (AOR) were recorded with 95\% confidence intervals (CI).

Results Compared to children with no impairment, children with behavioural $(\mathrm{AOR}=0.33$ [95\% CI: 0.03 to 3.35]) or non-behavioural $(\mathrm{AOR}=1.23$ [95\% $\mathrm{CI}$ : 0.32 to 4.35$]$ ) impairment were no more likely to suffer scalds than non-scalds. Furthermore, children with behavioural impairment (compared to non-impaired children) were more likely to have FT than non-FT burns $(\mathrm{OR}=8.33$ [95\% CI: 2.10 to 33.0]). This effect remained when adjusting for individual factors i.e. age and sex $(\mathrm{AOR}=5.76$ [95\% CI: 1.38 to 24.0]) but attenuated after adjusting for family (ethnicity, supervision levels, history of domestic violence in home and social workers) and environmental factors (IMD and location of burn event). Furthermore, children with behavioural impairment were less likely to have CRW first aid than those with no impairment $(\mathrm{OR}=0.26$ [95\% CI: 0.07 to 0.97$])$. This effect remained when individual and family factors were adjusted for $(\mathrm{AOR}=0.32[95 \%$ CI: 0.11 to 0.88$]$ ).

Conclusions Children with impairment are not at more risk of having scalds compared to non-scalds; full thickness burns or lesser likelihood of having CRW first aid (after controlling for confounding factors) compared to children with no impairment.

Acknowledgement This project was sponsored by funds from the Scar Free Foundation, an $\mathrm{NGO}$ /charity involved in injury research.

\section{G434(P) VIOLENT YOUTH CRIME PRESENTING TO AN INNER CITY DISTRICT GENERAL HOSPITAL: CLOSING THE GAP BETWEEN PAEDIATRICS AND PUBLIC HEALTH}

C Wijemanne, C Head, S Panjwani, E Blackburn. Community Paediatrics, Lewisham and Greenwich NHS Trust, London, UK

10.1136/archdischild-2018-rcpch.423
Aims Within an inner city borough the Child Death Overview Panel recognised an increase in deaths associated with violent youth crime, with 4 reported deaths between September 2015 and August 2016. It was unclear whether this represented a wider problem concerning violent youth crime within the local community. This study sought to investigate recent trends in youth attendances to the local Emergency Department (ED) related to violent crime.

Methods We conducted a single-centre retrospective observational study of all youth ( $<18$ years) attendances to the ED of a large district general hospital, over 4 years (November 2012 September 2016) with injuries associated with violent crime. Cases were filtered using key word search of the triage description, diagnosis field or free text fields using words associated with violent crime. Files were then manually reviewed by the authors to select relevant cases.

Results During the 4 year study period there were 122 ED presentations associated with violent youth crime. The average age was 14.9 years and the majority male $(70.5 \%, \mathrm{n}=86)$.

During the study period the number of presentations increased from 26 in the 1 st half of the study period to 96 in the 2 nd half. There was a significant increase in the proportion of cases involving female patients, from $7.7 \%(2 / 26)$ in the first half of the study period to $35.4 \%(34 / 96)$ in the 2 nd half $(\mathrm{p}=0.007)$.

A number of vulnerability factors were also frequently seen within the cohort, including past involvement of children's social care or CAMHS, a history of school exclusion or referral to pupil referral units, and a diagnosis of ADHD, Autism or cognitive delay.

Conclusion This study demonstrates an increase in local youth ED attendances with injuries related to violent crime, with rising numbers of female attendees over the last 2 years. This data was presented to stakeholders including representatives from Public Health, ED, the local MP and the charity sector. An application has been made for funding from the local mayor for an ED based youth worker.

\section{G435(P) MAKING EVERY CONTACT COUNT - A PAEDIATRIC PILOT TRAINING PROGRAMME IN WALES}

S Webster. Royal Gwent Hospital, Aneurin Bevan Health Board, Newport, UK

\subsection{6/archdischild-2018-rcpch.424}

Introduction A key recommended from the RCPCH State of Child Health report includes health promotion training for health professionals in order to 'make every contact count' (MECC). In order to pilot such a resource, a Public health training programme providing an evidence-based approach to motivational interviewing for behaviour change was adapted for those within the paediatric profession.

Methods The 'Making every contact count' level 1 and 2 training programme was adapted and combined into a twohour training session. This was delivered at a paediatric trainee study day in May 2017 and a health board clinical governance day in July 2017.

Results There were 41 trainees in attendance at the trainee study day. 14 paediatric consultants and 24 paediatric nurses attended the clinical governance session. A total of 57/79 (73\%) matched pre- and post-evaluation questionnaires were included for feedback analysis. Through a 5 point Likert scale the pre-session survey highlighted 57\% (32/57) strongly agreed 